\title{
Weather, clothing and thermal adaptation to indoor climate
}

\author{
Craig Morgan, Richard de Dear*
}

Division of Environmental and Life Sciences, Macquarie University, Sydney, New South Wales 2109, Australia

\begin{abstract}
The adaptive thermal comfort model links indoor comfort temperatures to prevailing weather outdoors, shifting them higher in warm weather and lower in cool weather. Adaptive comfort engineering standards hold the potential to conserve energy, but for them to work effectively it is essential that building occupants are free to adapt themselves, primarily through clothing adjustment, to the variable indoor climatic regimes prevailing inside such buildings. This paper examines clothing behaviour and its relationship with thermal environments in 2 different indoor settings located in Sydney, Australia. The first was in a suburban shopping mall, and the second in a callcentre office. The company operating the call-centre had a strict business attire dress-code in force Mondays through Thursdays, but on Fridays employees were free to wear casual clothes. Indoor temperatures throughout both studies were relatively static despite significant weather and seasonal trends operating in the outdoor atmospheric environment. Clothing insulation values of garments worn inside the shopping mall showed significant day-to-day variation, with the standard deviation representing about $34 \%$ of the mean clo $\left(1 \mathrm{clo}=0.155 \mathrm{~m}^{2} \mathrm{~K} \mathrm{~W}^{-1}\right)$ value during the study period. Typical shopping mall clo values during summer were more than 0.6 clo lighter than those worn in winter, and a regression model of daily average clo on daily mean outdoor temperature explained $52 \%$ of the variance in clo values. Clothing insulation levels worn on 'strict business attire' days in the callcentre study were relatively static, regardless of weather or season, and they showed only a weak statistical relationship with indoor temperature variations $\left(\mathrm{R}^{2}=20 \%\right)$. In contrast, the much more variable clo values worn by the office workers on 'casual' days, showed a significant correlation with outdoor temperatures $\left(\mathrm{R}^{2}=44 \%\right)$. Based on these relationships, an adaptive comfort model for use in hybrid ventilation buildings is proposed.
\end{abstract}

KEY WORDS: Thermal comfort · Hybrid insulation · Clothing insulation · Adaptive comfort model · Indoor climate $\cdot$ Energy conservation

Resale or republication not permitted without written consent of the publisher

\section{INTRODUCTION}

Clothing can be looked at from a variety of perspectives. It can be described in physical terms with respect to thermal resistance or insulation (Gagge et al. 1941, ASHRAE 1997) and its impedance to mass (water vapour) transfer (Woodcock 1962, Goldman 1981). From an ergonomist's perspective, clothing can be regarded as a mechanism capable of making a workplace environment safer and healthier for workers, or in some cases, present a workplace hazard. From an anthropological perspective clothing represents a significant cultural development that has, along with shelter and fire, allowed the species to venture well outside its original tropical domain (McIntyre 1980, Clark \& Edholm 1985, Parsons 1993). From a social angle, clothing can be variously thought of as a projection of personality, mood, religion, sub-cult and other group affiliations. Clothing also represents a code for organisational or corporate identity, and of course it is very commonly used to convey socio-economic status cues. But in conventional thermal comfort theory, perhaps most eloquently described by Fanger in 1970, clothing simply represents a single layer of thermal insulation uniformly interposed between the human subject's body surface and their immediate thermal environment. 


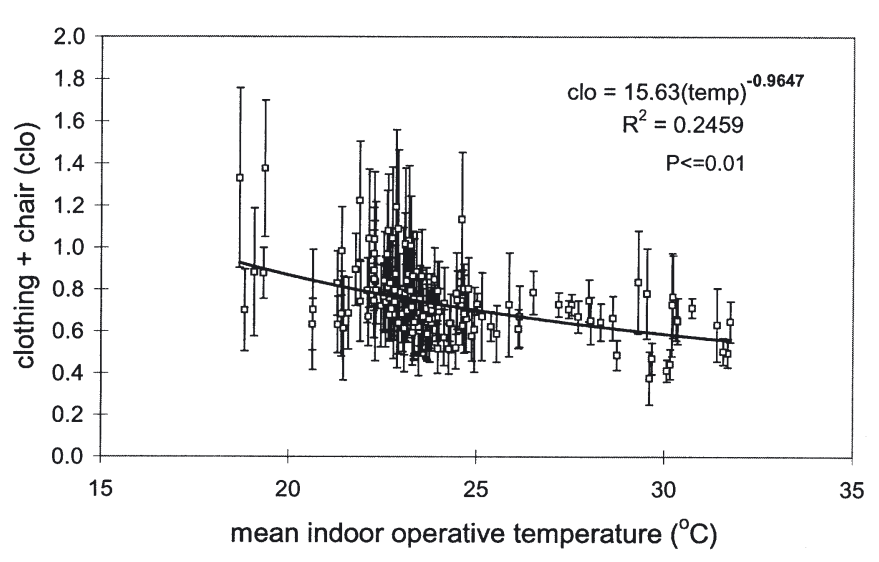

Fig. 1. The relationship between clothing insulation levels worn inside buildings (naturally ventilated and air-conditioned) and the mean indoor temperatures in those buildings. The data are from the ASHRAE global thermal comfort database (de Dear 1998). Each point represents a building average clothing insulation, as estimated by a standardised garment checklist and calibrated against the methods set out in ASHRAE Standard 55 (1992). Indoor temperatures are based on the operative temperature index, which is an arithmetic average of air and mean radiant temperatures. Error bars represent \pm 1 standard deviation of the building sample's clo value estimates. Clo estimates include the incremental effect of the upholstered chair upon which the subject was sitting at the time of the questionnaire (ca. 0.15 clo)

The significance of this heat-balance parameter has not escaped the attention of adaptive comfort model proponents, who advocate wider indoor temperature ranges than conventional comfort standards and practices currently permit, with a view to conserving energy in the built environment (Humphreys 1979, Auliciems 1986, de Dear \& Brager 1998, 2001). Empirical evidence of the role played by clothing insulation in adapting to indoor climate can be seen in Fig. 1. Taken from de Dear \& Brager's global intercomparison of thermal comfort field studies, the graph indicates that the mean thermal insulation ${ }^{1}$ worn inside any single building (mostly offices) tends to correlate negatively with average temperatures inside the building (de Dear \& Brager 1998, 2001). Based on some 22000 questionnaire responses across 160 different buildings scattered across 4 continents, the regression relationship depicted in Fig. 1 accounts for about a quarter of the total between-building variance in average indoor clothing insulation estimates, suggesting that indoor temperature is an important determinant of clothing behaviour indoors but also that there are many other influences as well as some random variability.

The field evidence reported above is further reinforced by recent longitudinal observational studies

\footnotetext{
${ }^{1}$ One clo approximates the thermal insulation value of a heavy winter business suit, or $0.155 \mathrm{~m}^{2} \mathrm{~K} \mathrm{~W}^{-1}$
}

that indicate building occupants modify their clothing several times throughout the day, largely in response to non-steady-state thermal comfort conditions indoors (Baker \& Standeven 1996, Newsham \& Tiller 1997). On average, $15 \%$ of the occupants in their Canadian office buildings modified their clothing during the hour prior to interview. Even minor adjustments such as loosening a neck-tie or rolling up shirt-sleeves, which would be barely measurable using contemporary thermal manikins, should be regarded as purposive thermoregulatory behaviour.

Another feature of Fig. 1 is the remarkable difference in clothing variability across different buildings, as indicated by the error bars ( \pm standard deviation) around each building's mean clo value. At one extreme there are buildings where the central 2 standard deviations in clo span a range of 1.0 clo, while at the other extreme the within-building heterogeneity is less than 0.1 clo. The reasons for such diversity in within-building clo variance are many and varied, some biophysical and others social. An obvious biophysical hypothesis is the degree of indoor climatic homogeneity. The more spatially and temporally diverse the indoor conditions within a building, the more variable the clothing responses by that building's occupants. Another factor explaining diversity of within-building clo variances is the overall level of warmth prevailing inside the building. Fig. 1 demonstrates converging insulation values, both between and within buildings, as indoor temperatures increase. This suggests that the degrees of freedom for clothing behavioural thermoregulation diminish as the number of garments decreases towards a socially acceptable minimum level, ca. 0.45 clo (or 0.6 clo in Fig. 1, which includes an average insulation increment of 0.15 clo for the office chair being used at the time of questionnaire).

As noted earlier, clothing insulation levels are not determined solely by indoor climatic factors. Diversity among the occupants themselves could also contribute to differing within-building clo variances. For example, a building with exclusively same-sex occupants could be expected to have greater homogeneity in clo values than one with both females and males. There has long been recognition of a difference between the insulation values worn by males and females occupying the same office, with women wearing significantly less than males in summer, and more in winter (e.g. de Dear \& Brager 1998, 2002). There is also an organisational factor contributing to the diversity of clo variances depicted in Fig. 1. Nearly all the buildings in the sample were commercial or governmental offices, and these organizations often have dress codes regulating what their employees can and cannot wear in the workplace. By prescribing strict clothing standards or even uniforms, these more formal dress codes carry 


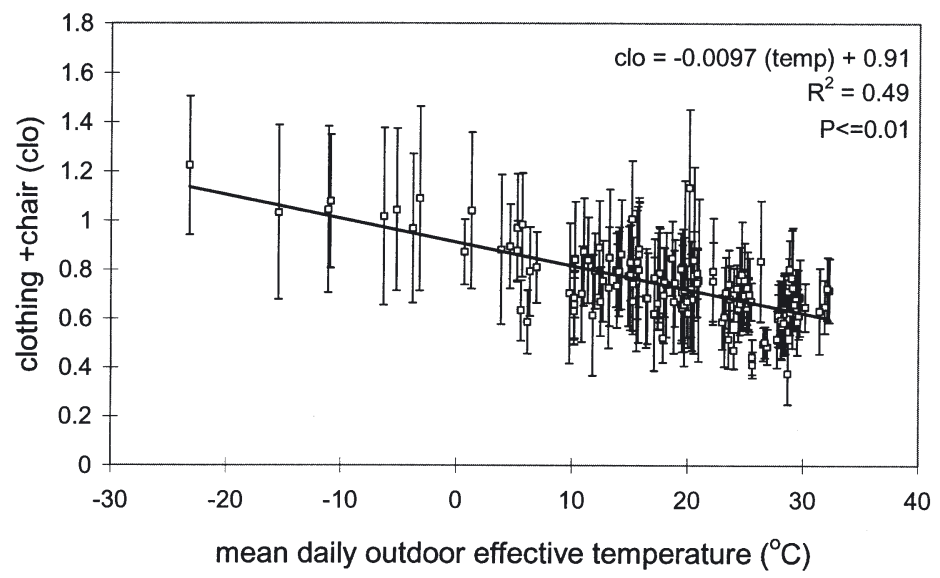

Fig. 2. Relationship between the mean thermal insulation worn inside buildings in the de Dear \& Brager $(1998 ; 2001)$ study and the mean outdoor effective temperature $\left(E T^{*}\right)$ at the time of the study. The latter was calculated as the average of daily minimum $E T^{*}$ (air temperature, relative humidity and clo values as input) and daily maximum $E T^{*}$

significant implications for the adaptive model of thermal comfort-namely, they limit thermal adaptive opportunities for employees in office workplaces.

Indoor clothing insulation levels also reflect outdoor environmental conditions. The adaptive comfort model protagonists have long argued that building occupants respond not only to the thermal regimes inside their buildings but to the weather and seasonal conditions prevailing outdoors as well (Auliciems 1981, Humphreys 1981, de Dear \& Brager 2001). This hypothesis arises from the common-sense observation that weather forecasts are routinely issued during the morning, at a time when they can affect clothing-wardrobe decisions. But of course another clothing-weather linkage is the fact that thermal regimes inside certain types of buildings are actually correlated to varying extents with temperatures prevailing outside the building. This is particularly so in the case of 'free-running' (neither heated nor cooled) buildings, or those with natural ventilation. Fig. 2 depicts the relationship between the mean thermal insulation worn inside buildings in the de Dear \& Brager $(1998,2001)$ study and the mean outdoor effective temperature $\left(E T^{*}\right)$ at the time of the study. The strength of the relationship is summarised by the $\mathrm{R}^{2}$ statistic (coefficient of determination), which indicates that about half ( $49 \%$ ) of the between-building variance in clo values was explained by variations in outdoor atmospheric conditions.

Despite these direct and indirect linkages between clothing on the one hand and both indoor and outdoor climates on the other, the thermally regulable dynamics of clothing behaviour are often overlooked in today's thermostatically regulated workplaces. Anthropologists would indicate that clothing, as a part of material culture, originally evolved to insulate ourselves from thermal situations that we find unacceptable or indeed stressful (Parsons 1993), but in contemporary urban societies, where it is typical to spend more than $90 \%$ of our lives indoors (Fanger 1970), the responsibility of thermoregulation seems to lie now wholly with air-conditioning systems and not the individual building occupant (Fountain et al. 1996). This shift in 'thermal comfort responsibility' adds further importance to the regulation and development of indoor climate standards such as ASHRAE Std 55-92 (ASHRAE 1992). It also diminishes the thermoregulatory significance of clothing, allowing the non-thermal factors identified earlier to gain ascendancy in clothing decisions. For example, since indoor climates can be engineered to suit any arbitrarily chosen clothing insulation level, office-based workplaces are now free to enforce whatever style and quantity of clothing they deem appropriate to their corporate image. The end result has been a globalisation of indoor clothing patterns, with office workers in the humid tropics of Southeast Asia, for example, wearing very similar business suits to their counterparts in temperate or even subarctic climate zones. We can, and do, wear whatever we like indoors in virtually every climate zone on the planet, providing we are prepared to pay the financial and environmental costs of heating, ventilation and air-conditioning (HVAC) energy (Fountain et al. 1996).

However, it would be wrong to construe contemporary clothing behaviour as totally devoid of any rational basis (Clark \& Edholm 1985). Markee White (1986) investigated the various factors impinging upon clothing garment and ensemble choices of office workers in North America. Using a questionnaire it was noted that the salient factors were, in order of importance: (1) comfort (non-thermal wear factors), (2) anticipated outdoor environment, (3) anticipated indoor environment, (4) appropriateness for the job, (5) desire to be fashionable, (6) dress code, and (7) after-work activities.

The same subjects said that they could have dressed more comfortably for work were it not for (in order of importance): (1) inappropriateness for the job, (2) dress code of their workplace, (3) inability to anticipate indoor conditions, (4) desire to be fashionable, and (5) lack of more comfortable clothing options in their wardrobe. The first 2 factors in this list appear to be related - the first one is like an 'unwritten' dress code, whereas the second is a clearly articulated policy on what is permissible clothing.

Five research hypotheses arise from this literature review of clothing, thermal comfort, and indoor- and outdoor climate, and these are the foci of the research reported here: 
- (1) There are gender differences in both levels and dynamics of clothing insulation worn indoors.

- (2) Clothing thermal insulation levels worn indoors are affected by context/setting (for example, office vs department store).

- (3) Clothing insulation levels worn indoors are affected by corporate dress codes (for example, the distinction between formal office attire and casual clothing).

- (4) Clothing insulation levels worn indoors are affected by the indoor climate variability.

- (5) Clothing insulation levels worn indoors are affected by the outdoor weather and climatic context of the building.

\section{METHODS}

We investigated these research issues by observing the clothing behaviour of subjects within 2 distinct research designs. First we used a cross-sectional study of patrons in a large suburban shopping mall. These observations were supplemented by a longitudinal study of a smaller sample of office workers in a modern open-plan office (a telemarketing call-centre). The particular buildings in which we performed the studies were selected on the basis of permission being granted by employers and tenants. The cross-sectional study was used to investigate average clothing insulation levels across a large sample (about 45 new subjects per day) every day for about 6 mo. The second study, longitudinal in design and of 5 mo duration, was used to track clothing behaviour in relation to indoor and outdoor climatic variations and to assess the impact of dress codes on adaptive opportunities.

\subsection{Shopping mall study}

The first study was conducted between August 1996 and January 1997 in a department store located within a shopping mall in the western suburbs of Sydney, Australia (latitude $34^{\circ} \mathrm{S}$ ). Every fourth adult subject to pass the observation station within the department store was unobtrusively observed by the researchers (Moser \& Kalton 1971), and their clothing insulation value rated in units of clo. The method of clo estimation was based on the garment check-list defined in ASHRAE Std 55-92 (ASHRAE 1992). The cumulative total of subjects' clothing garment effective insulation values was registered as the intrinsic insulation value of the composite ensemble. Table 1 lists the effective garment insulation values used in this study.

$$
I_{\mathrm{cl}}=\sum_{i} I_{\mathrm{clu}, i}
$$

where $I_{\mathrm{cl}}$ is the intrinsic insulation value of the composite ensemble and $I_{\mathrm{clu}, i}$ is the effective insulation value of the $i$ th garment.

Observations were made on every day of the $6 \mathrm{mo}$ period, providing an uninterrupted time series for statistical analysis. Observers were trained for $2 \mathrm{~d}$ on-site before the data reported in this paper were collected. Concurrent outdoor temperatures were obtained from an automated weather station less than $1 \mathrm{~km}$ from the shopping mall site. Indoor temperatures were recorded with a linearised composite thermistor connected to a

Table 1. Individual clothing garments and their effective insulation values (Iclu,i, clo). Ensemble intrinsic insulation values are derived by summing individual garment effective insulation values (after ASHRAE Standard 55-92)

\begin{tabular}{|lc|}
\hline Garment description & Iclu,i (clo) \\
\hline Bra & 0.01 \\
Panties & 0.03 \\
Full slip & 0.16 \\
Half slip & 0.14 \\
Men's briefs & 0.04 \\
T-shirt thin & 0.08 \\
Ankle socks & 0.02 \\
Calf socks & 0.03 \\
Knee socks (thick) & 0.06 \\
Pantyhose/stockings & 0.02 \\
Shoes & 0.02 \\
Boots & 0.10 \\
Sandals/thongs & 0.02 \\
Sleeveless blouse & 0.13 \\
Short-sleeve blouse & 0.19 \\
Short-sleeve knit sport shirt & 0.17 \\
Long-sleeve shirt & 0.25 \\
Long-sleeve flannelette shirt & 0.34 \\
Short shorts & 0.06 \\
Walking shorts & 0.08 \\
Short-sleeve T-shirt & 0.08 \\
Thin trousers & 0.15 \\
Thick trousers & 0.24 \\
Sweatpants & 0.28 \\
Overalls & 0.30 \\
Thin suit vest & 0.10 \\
Thick suit vest & 0.17 \\
Thick single breasted jacket & 0.36 \\
Thin double breasted jacket & 0.42 \\
Thick double breasted jacket & 0.44 \\
Thin sleeveless vest (sweater) & 0.48 \\
Thick sleeveless vest (sweater) & 0.13 \\
Thin long sleeve sweater & 0.22 \\
Thin skirt sleeve sweater & 0.25 \\
Thick skirt & 0.36 \\
Sleeveless dress thin & 0.14 \\
Short-sleeve dress thin & 0.23 \\
Long-sleeve dress thin & 0.23 \\
Long-sleeve dress thick & 0.29 \\
& 0.33 \\
& 0.47 \\
& \\
\hline & \\
\hline
\end{tabular}


portable datalogger with a logging interval of $10 \mathrm{~min}$. Typically there were about 45 different subjects assessed on any one day, providing the basis for a daily mean clothing insulation value.

\subsection{Office building study}

The second study was conducted in a typical 'Grade$\mathrm{A}^{\prime}$ air-conditioned office building in the central business district of Sydney, Australia. Between September 1997 and January 1998 a sample of 14 call-centre workers ( 7 female and 7 male) were studied in relation to their clothing insulation levels and thermal comfort. Their average age was approximately $35 \mathrm{yr}$. This office environment was fundamentally different to the shopping mall study because dress codes were in force. From Monday through Thursday of each week there was a strict business attire dress code in place, necessitating suits and other formal clothing. However on Fridays, the employer had a policy of relaxing the dress code and permitting staff to wear casual clothing (typically jeans, shorts and T-shirts).

The ScreenSurvey ${ }^{\mathrm{TM}}$ software (Newsham \& Tiller 1997) was used to gather data from a sample of 14 subjects. The software designed and presented questionnaires in the familiar Windows ${ }^{\mathrm{TM}}$ interface. It automatically 'popped up' on the subjects' workstation screens at least once each day. When the questionnaire popped up, the subject was required to go through a clothing garment checklist (see Table 1) and also to complete a small battery of thermal comfort questions (not reported in this paper). The whole questionnaire required less than 2 min to complete, but if the subject was busy when the questionnaire popped up, they could postpone it for up to an hour. The data were downloaded from the subjects' computers at the end of each working week and imported to our database for subsequent statistical analysis. On any one poll (every half-day) we registered responses from an average of 10 out of the 14 subjects.

Before reaching the clothing section of the software, subjects were required to indicate gender, and this response was used by the software's algorithm to present only the relevant half of the garment checklist from Table 1. The effective insulation values of each garment $\left(I_{\mathrm{clu}, i}\right)$ in the questionnaire checklist were coded into a look-up table (hidden from subject's view), and the final ensemble intrinsic insulation $\left(I_{\mathrm{cl}}\right)$ was automatically time-stamped and logged to the data-export file.

Local and concurrent outdoor meteorological data were obtained from the Australian Bureau of Meteorology's automated weather station (AWS) at Observatory Hill, within the Sydney central business district and less than $2 \mathrm{~km}$ from the office building under observation. The AWS temperature and humidity data were sorted into $15 \mathrm{~min}$ bins. All temperatures for the 15 min data periods within the building's office hours each day were averaged to yield a daily mean temperature.

Indoor temperatures for the call-centre were recorded by a pair of linearised composite thermistors, each connected to its own miniature datalogger. They were placed within the occupied zone of the call-centre. One was located on a structural pillar in the building's HVAC core zone, approximately $10 \mathrm{~m}$ from the external glazing. The other was within the zone where the workstation was located, $0.6 \mathrm{~m}$ above floor level. Local thermal effects produced by computers and other heat-emitting office equipment, supply air vents, and open doorways were taken into consideration when placing the temperature loggers.

\section{RESULTS}

The project's results are organised according the environment in which they were collected.

\subsection{Shopping mall results}

The outdoor weather observations during the shopping mall study are plotted in Fig. 3. They show the expected gradual increase in air temperatures from the austral spring into summer. The highest daily average outdoor temperature was recorded during a brief heatwave centred on 11 October, quite early in the austral spring. Other warm-to-hot spells with mean daily temperatures exceeding $25^{\circ} \mathrm{C}$ occurred on 14 November and again on 2 December. The overall mildness of Sydney's climate is evident in Fig. 3, which indicates mean daily temperatures above $10^{\circ} \mathrm{C}$ (July) and below $25^{\circ} \mathrm{C}$ (January). After ranking the mean daily temperatures for the entire 6 mo duration of the study we found the 10th percentile was $12.5^{\circ} \mathrm{C}$, the 90th percentile was $22.1^{\circ} \mathrm{C}$, while the median (50th percentile) was $17.3^{\circ} \mathrm{C}$. This median temperature came within half a degree of the long-term climatological mean for western Sydney (Bureau of Meteorology 1991), suggesting that the 6 mo study period was climatically typical for the region. Despite the minor seasonal contrasts in temperature for this part of the world, the day-to-day standard deviation in mean outdoor temperature of $3.8^{\circ} \mathrm{C}$ suggests a fairly changeable synoptic environment during the 6 mo study period.

Indoor air temperatures within the shopping mall are also plotted in Fig. 3. The graph indicates a very restricted range of indoor temperatures throughout the 


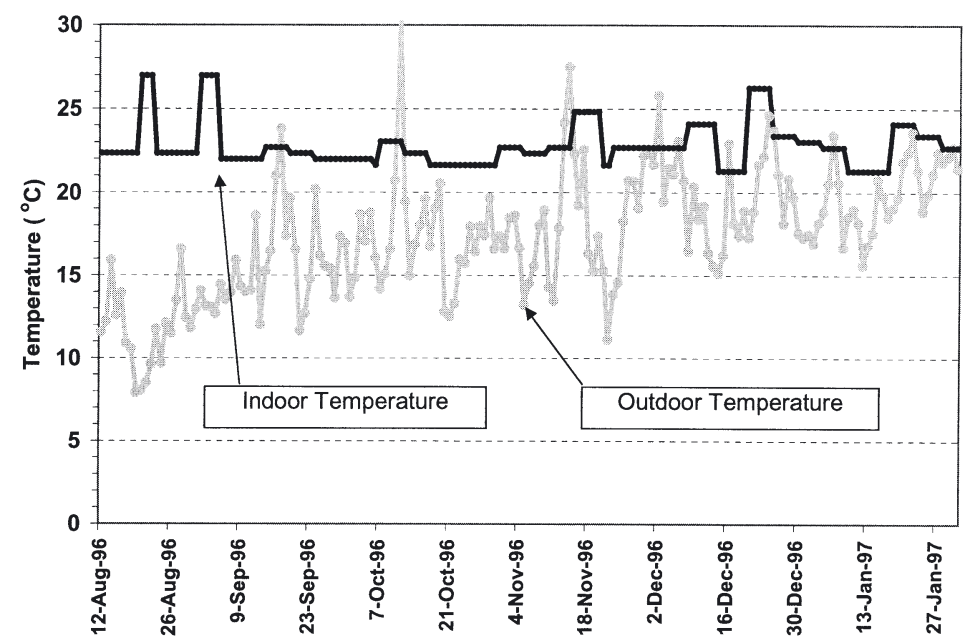

Fig. 3. Indoor and outdoor daily average temperatures during the shopping mall study

6 mo study, despite significant external air temperature variability. Indoor temperatures were generally contained within the 22 to $24^{\circ} \mathrm{C}$ band. The observation of just 3 indoor temperature excursions above $25^{\circ} \mathrm{C}$ throughout the entire $6 \mathrm{mo}$, two of which fell in winter months, underscores the absence of any seasonal adaptation in the shopping mall's HVAC system.

Overall, the clothing style observed in the mall study could best be classified as 'casual'. The daily clo values plotted in Fig. 4 are averaged across all subjects assessed on a given day (sample size ca. 45). Daily mean clo values trend downwards from winter through spring and into summer. Apart from the anomalously low-clo week at the start of the study, mean wintertime clothing insulation values were generally in the $0.7-0.9$ clo range, dropping to the $0.3-0.5$ clo range by mid-summer (January).

Fig. 5a shows the scatterplot of daily mean indoor temperature and daily mean clo values. The statistically insignificant regression model $(F=0.77, \mathrm{p}=0.37, \mathrm{df}=1,171)$, with a negligible coefficient of determination $\left(\mathrm{R}^{2}=\right.$ 0.0045), suggests that clothing insulation levels worn inside the department store were independent of temperatures prevailing within the store. Fig. 5b is a regression of mean daily clo observations on mean daily outdoor temperature, as recorded at the nearby automatic weather station. The regression model was highly significant $(F=188.4$, $\mathrm{p}<0.0001$, df $=$ $1,171)$, with $52 \%$ of the day-to-day variance in mean daily clo values being accounted for by the relationship with daily outdoor temperature. Of the various regression function options we found that a power function maximised the explained variance $\left(\mathrm{R}^{2}\right)$ in this case. Fig. 5b indicates a gradual decay of indoor clo values from $\sim 0.9$ on the coldest days (mean outdoor temperatures below $10^{\circ} \mathrm{C}$ ) towards a minimum daily average clo of $0.2-0.3$ clo on the warmest days (mean outdoor temperatures above $25^{\circ} \mathrm{C}$ ).

The statistical association between daily mean clo values and outdoor temperatures was extended beyond the

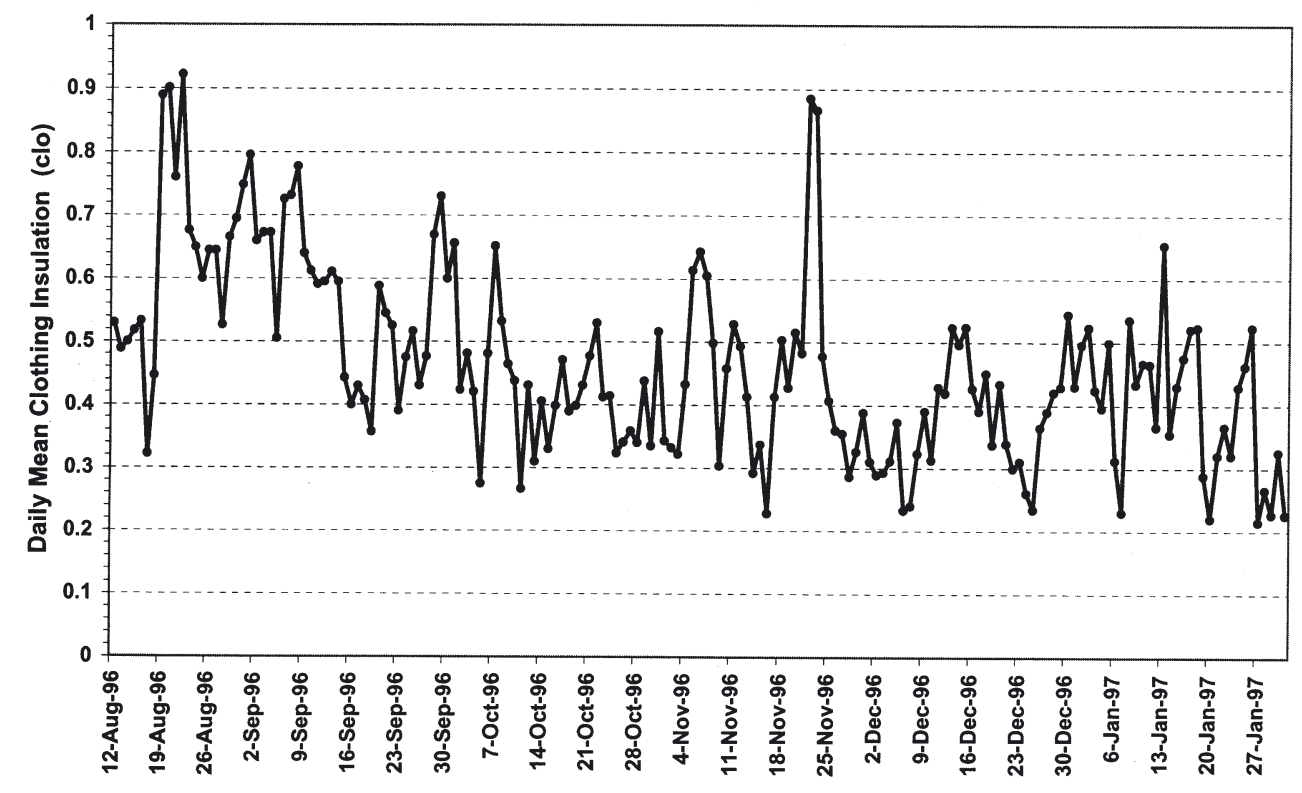

Fig. 4. Daily averaged clothing insulation values in the shopping mall study 

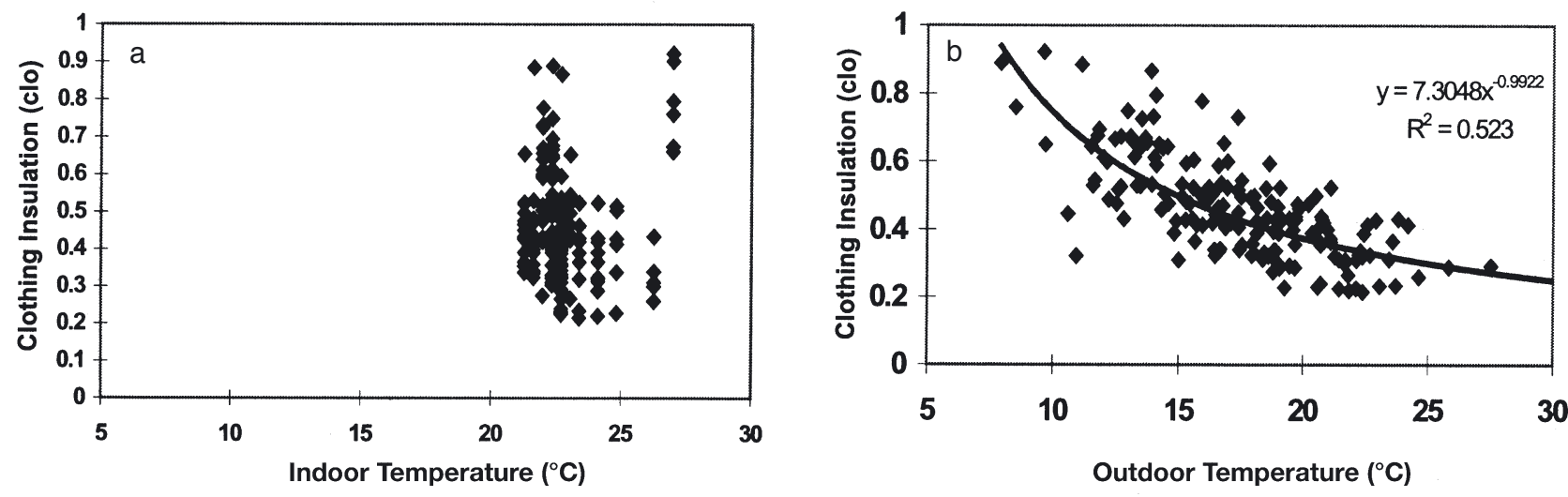

Fig. 5. Regression between mean daily clothing and mean daily (a) indoor and (b) outdoor temperatures during the shopping mall study

day on which the clo measurements were taken, to several days preceding. Pearson product-moment correlation coefficients were calculated between daily mean clo value on Day $x$ and daily mean outdoor air temperatures on Day $x-1$, Day $x-2$, Day $x-3$... Day $x-7$. Fig. 6 shows the strength of correlation (expressed as $\mathrm{R}^{2}$ ). A gradual decay in correlation between Day $x$ clo and outdoor temperature is evident as the time-lag increases from 0 to $7 \mathrm{~d}$. An exponential regression model fitted to the series of 8 time-lagged coefficients of determination $\left(\mathrm{R}^{2}\right)$ was able to explain $97 \%$ of the variance. All 8 regression coefficients were statistically significant at better than 0.05 probability. In contrast there was no apparent relationship, statistical or otherwise, between daily mean clo values and indoor temperatures, regardless of which timelag was applied.
Gender represents another dimension in the clothing matrix that can be examined with this data set. While no questionnaire was actually administered to subjects in the shopping mall study, our field researchers were required to record gender to enable the correct clovalue look-up table (Table 1) to be used when subsequently estimating garment and ensemble insulation values.

Table 2 indicates that female subjects wore, on average, marginally warmer clothing than the males. But perhaps more important to the focus of this paper is the observation that females registered greater variability in their daily mean clo values than the males. This can be seen in Fig. 7, with both genders' regression models being statistically significant at better than 0.05 probability.

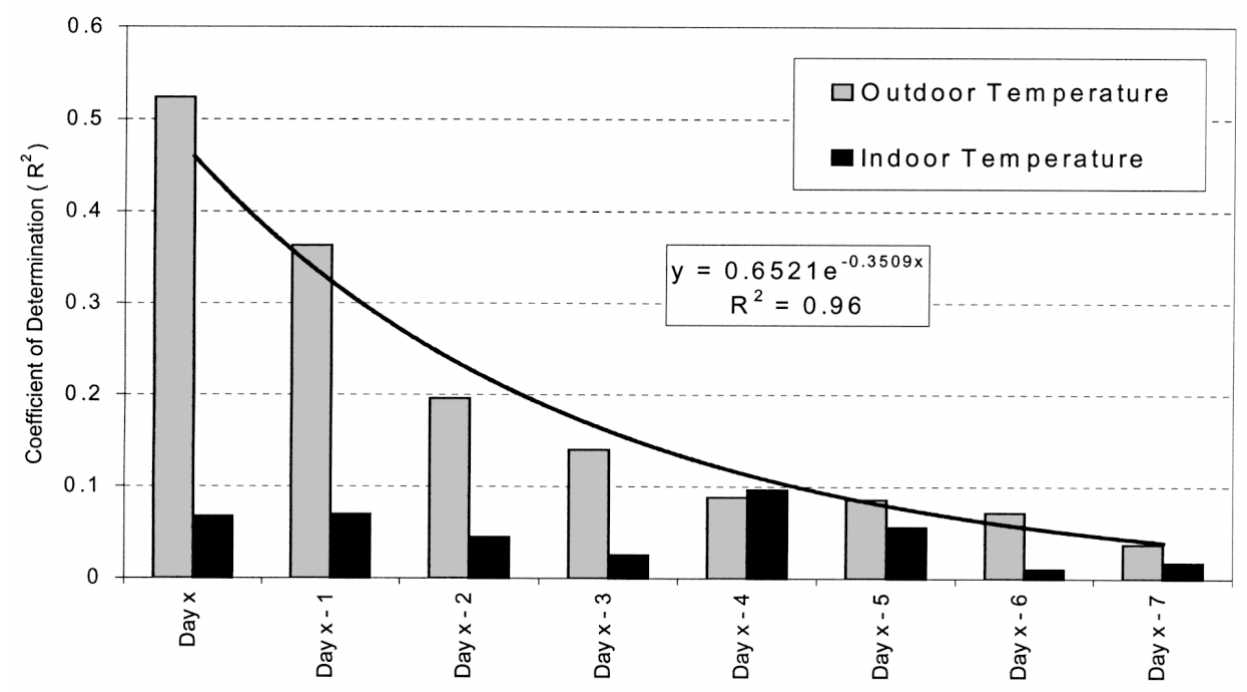

Fig. 6. Coefficients of determination $\left(\mathrm{R}^{2}\right)$ for the relationship between mean daily indoor clothing insulation and indoor/outdoor average temperatures across various time-lags (from 0 to $8 \mathrm{~d}$ ). All 8 coefficients were statistically significant at better than the 0.05 level 
Table 2. Mean ensemble insulation values (clo) observed in the shopping mall study broken down by gender

\begin{tabular}{|lcc|}
\hline & Female & Male \\
\hline $\begin{array}{l}\text { Mean ensemble insulation } \\
\text { values }\end{array}$ & 0.51 & 0.47 \\
$\begin{array}{l}\text { Standard deviation of daily mean } \\
\text { insulation values }\end{array}$ & 0.18 & 0.15 \\
\hline
\end{tabular}

\subsection{Office environment results}

Fig. 8 shows the gradual upward trend of mean daily temperatures from about $15^{\circ} \mathrm{C}$ in October up to the mid-20s in January during the office environment study. The office building was largely unoccupied during the weekends, hence the weekly truncations in the time-series in Fig. 8.
Fig. 9 shows indoor the temperature observations during the office environment study. As was the case with the shopping mall study, there was a relatively homogeneous mean daily indoor temperature throughout the study period. However, the actual temperatures recorded in the office, in the mid-20s, were generally a few degrees higher than those recorded in the shopping mall study. Fig. 9 indicates a significant amount of temperature variation within each working day at the call-centre, with ranges of 5 to $6^{\circ} \mathrm{C}$ being typical during office hours.

Intrinsic ensemble thermal insulation values were calculated and a daily averaged clo figure determined by the on-screen questionnaire software automatically after the subject had completed the garment checklist. The subjects' employer had a strict 'business attire' dress code policy on the days between Monday and Thursday. On Fridays, conversely, the dress code was 'casual'. Fig. 10 shows the plot of all clothing insulation results, with Fridays being last data point in each string
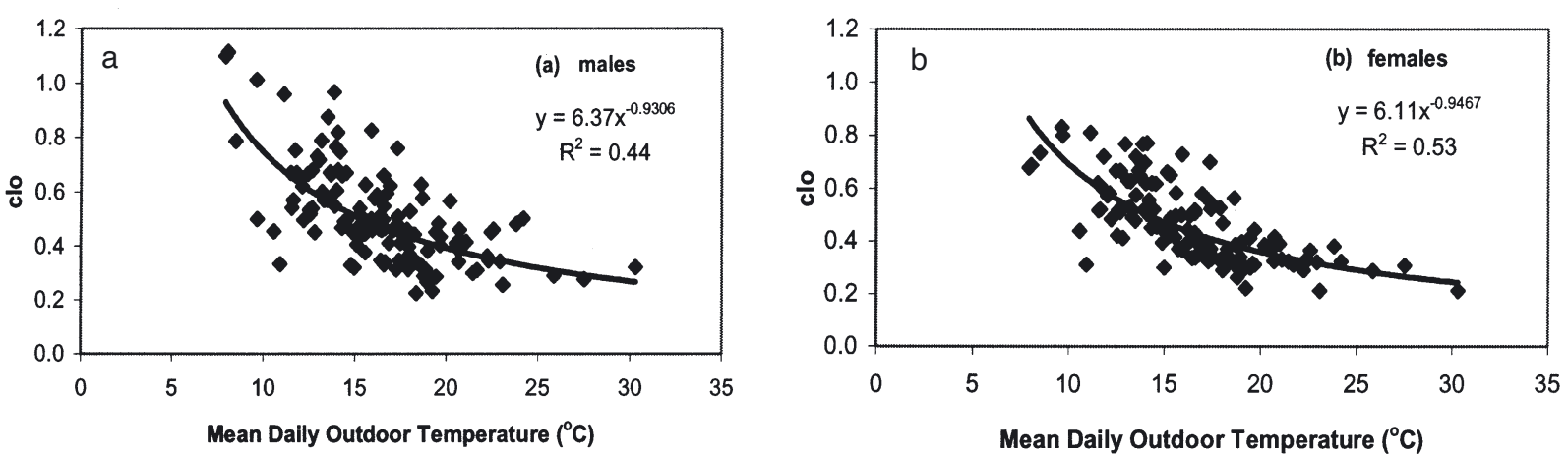

Fig. 7. Regressions between (a) male and (b) female mean daily clothing insulation values and mean daily outdoor temperatures during the shopping mall study

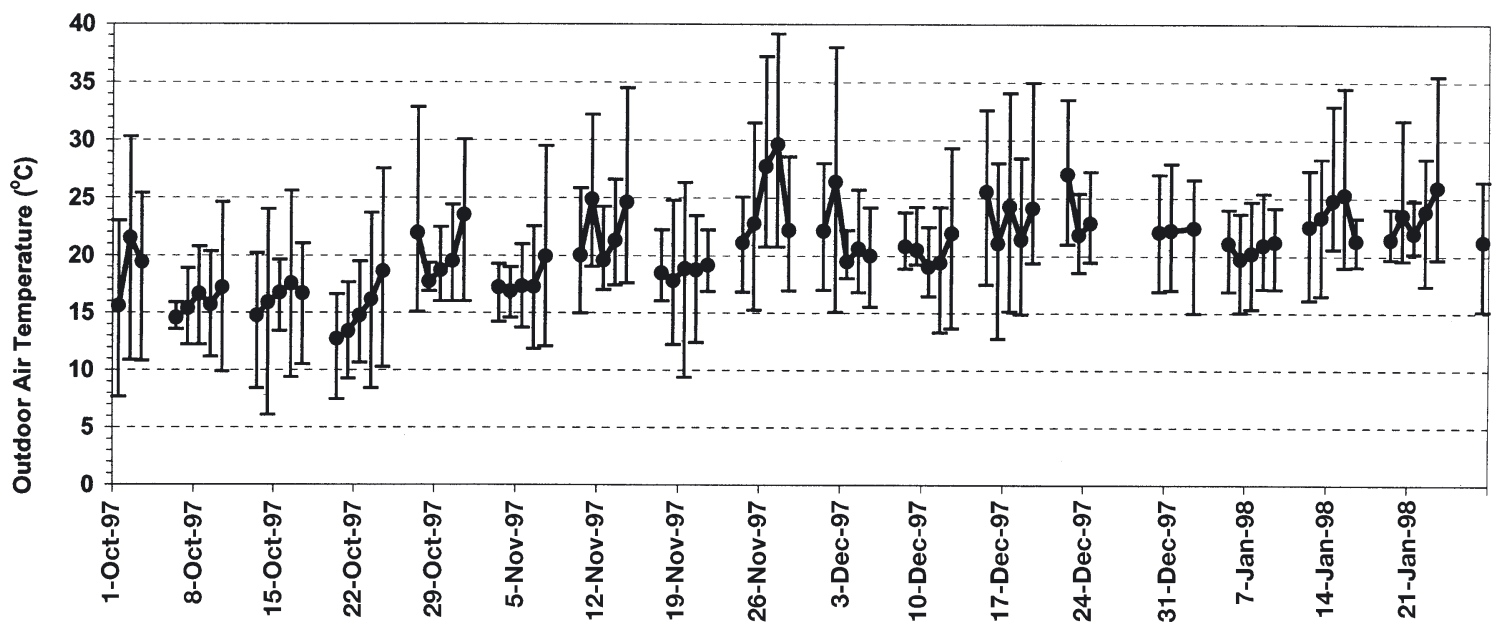

Fig. 8. Average daily outdoor air temperature during the office environment study, with daily minima and maxima superimposed 


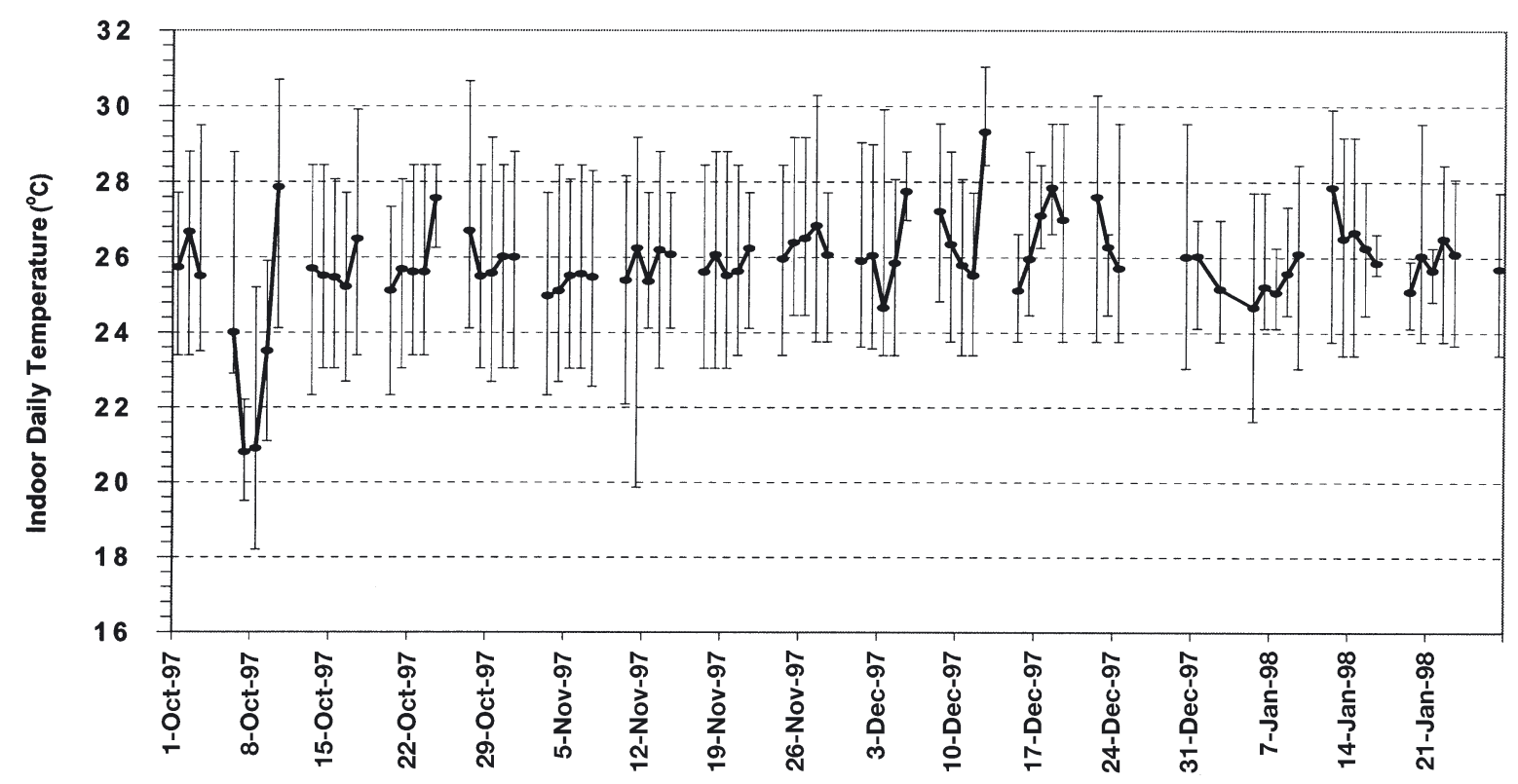

Fig. 9. Mean temperatures indoors during office hours, with daily minimum and maximum superimposed, during the office environment study

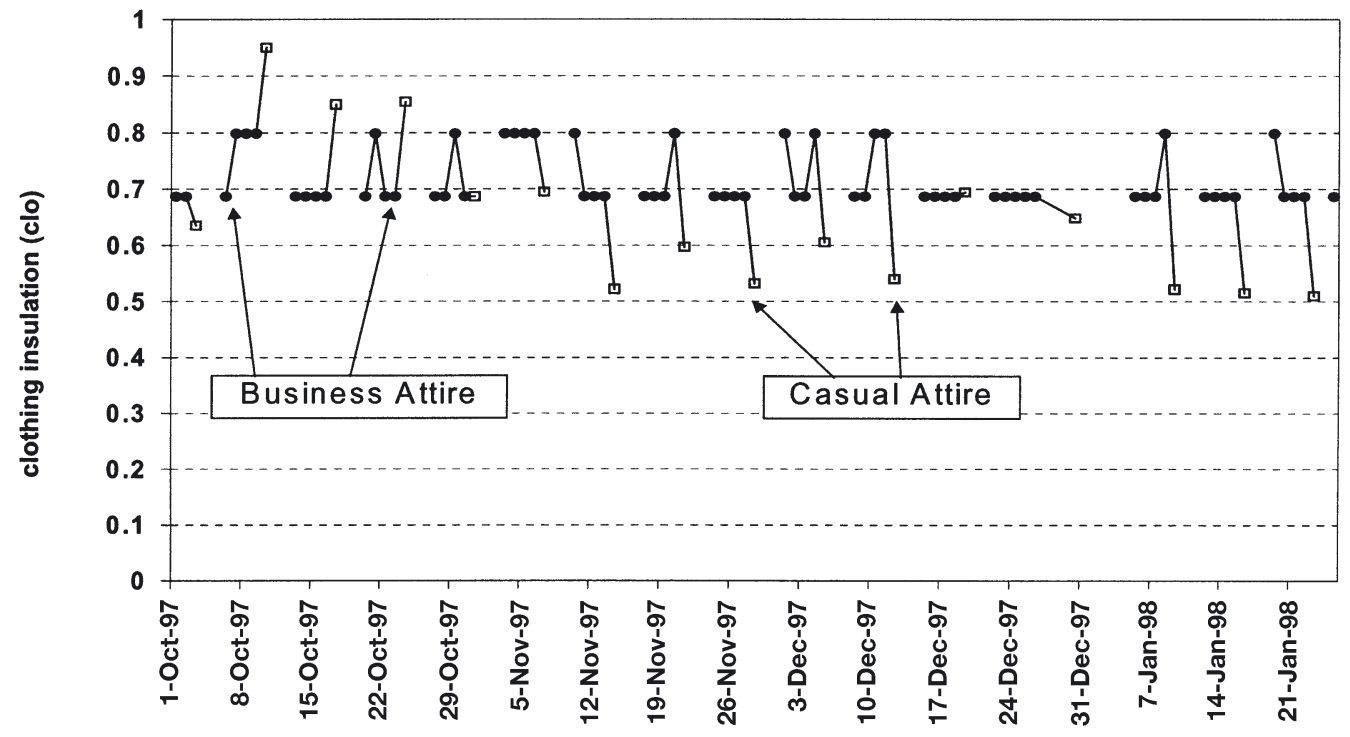

Fig. 10. Daily averaged clothing insulation during the office environment study

of 5. The daily averaged (across all subjects) clo values observed on Friday's were noticeably higher than the other weekdays' values in winter, and lower in summer.

The statistical relationships between average daily clothing insulation being worn indoors and mean daily temperature, both indoors and out, were assessed by regression analysis. $\mathrm{R}^{2}$ for the indoor office-hours temperature model is negligible at $0.0026(F=0.2, \mathrm{p}>0.05$, df $=1,79$ ). The regression model between daily mean outdoor temperature and all clothing data has a significant $\mathrm{R}^{2}, 0.143$, but it is also relatively small $(F=12.9$, $\mathrm{p}<0.05$, df $=1,79$ ).

The clear differentiation of clothing styles into 'business' (Monday through Thursday) or 'casual' (Friday) attire invites another way of looking at the data. Fig. 11 shows the relationship between mean daily indoor clothing data identified as business attire 

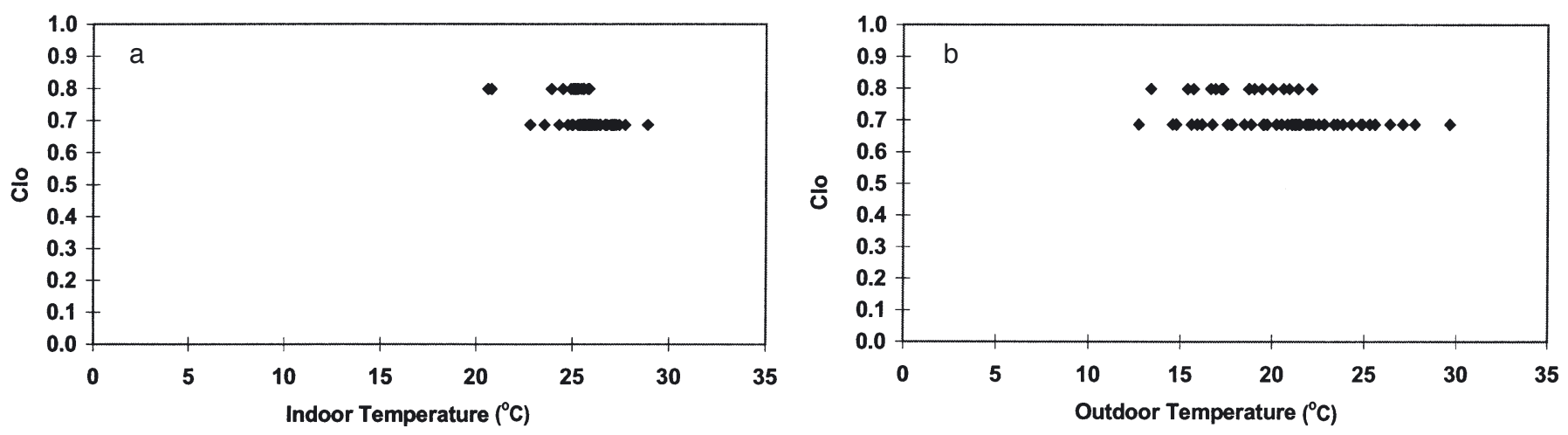

Fig. 11. Regression of Monday-Thursday (business attire) clothing insulation estimates on (a) indoor and (b) outdoor mean temperatures. Data from the office environment study
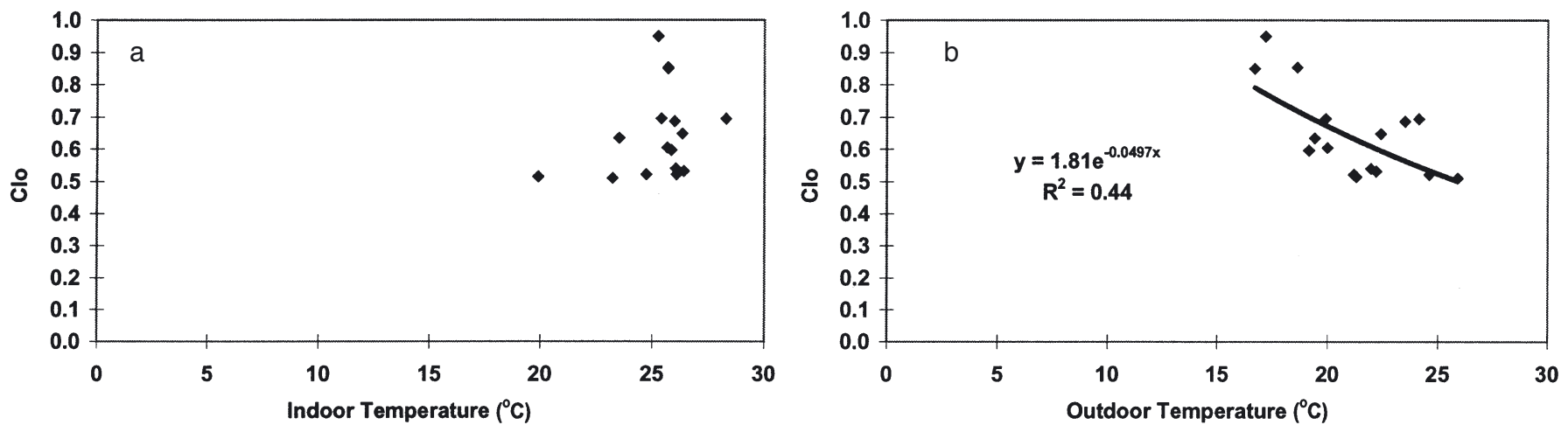

Fig. 12. Regression of casual Fridays (mufti day) clothing insulation estimates on (a) indoor and (b) outdoor mean temperatures. Data from the office environment study

and both indoor and outdoor daily average temperature. The binary group-average daily clo values recorded on business attire days show negligible dependence on either indoor or outdoor temperatures.

Insulation values of clothing ensembles worn on 'casual Fridays' (i.e. mufti ${ }^{2}$ days) are plotted in relation to indoor and outdoor temperature in Fig. 12. Despite the apparent positive relationship between mean daily office-hours indoor temperature and mean casual clothing insulation estimates in Fig. 12a, the small $\mathrm{R}^{2}$ (0.10) was statistically insignificant $(F=1.2, \mathrm{p}>0.05$, df $1,16)$. In contrast, $44 \%$ of the variance between daily mean clo values on casual Fridays was accounted for by the regression relationship with mean daily outdoor temperature (Fig. 12b; $\mathrm{R}^{2}=0.44, F=11.26$, $\mathrm{p}<0.01$, df $1,16)$.

${ }^{2}$ The word mufti (pronounced $\backslash$ muf'ti $\backslash_{\text {, }}$ ) was once used to describe civilian clothes when worn by a naval or military officer; a term derived from the British service in India

\section{DISCUSSION}

\subsection{Data-accuracy issues}

Chapter 8 of the ASHRAE handbook of fundamentals (ASHRAE 1993) indicates that the most accurate methods for determination of clothing insulation are (1) measurement on thermal manikins (McCullough \& Jones 1984, Olesen \& Nielsen 1983) or (2) direct measurements of skin and clothing surface temperatures along with clothing-layer heat fluxes ((Nishi et al. 1975, Danielsson 1993). Estimation of ensemble insulation values from checklists of published garment values is suggested in the ASHRAE handbook of fundamentals to have an accuracy of the order of $\pm 25 \%$ of the benchmark thermal manikin measurements (ASHRAE 1993). Explanations for the discrepancies are legion, but uppermost would be the differences in fabric weave, materials and fabric weight, not to mention variations in garment and ensemble fit which, in turn, modify the amount of sub-clothing layer air available to thermally insulate the subject. The on-screen 
clo-checklist method used in the office environment study would be subject to the $\pm 25 \%$ errors suggested by ASHRAE. Such an error figure is far from ideal, but the decision to use real office workers in a field setting precluded any of the laboratory methods described above. Whatever errors exist in our raw data, they are unsystematic and uniformly distributed throughout the sample.

The method of clothing insulation estimation used in the shopping mall study is probably subject to errors even larger than those discussed above, because the researchers were unable to actually speak to the subjects or get them to complete a garment checklist. The trained-observer method represents the only practicable solution to the need for high-speed unobtrusive observations in a real-world setting. A case could be made that a trained observer would be more reliable at classifying garments into the checklist than the subjects themselves, but there remains the problem of unobserved garments or clothing layers hidden from our observers' view. Given the relatively mild climatic setting of Sydney, we expect that the overwhelming majority of hidden garments worn by subjects in the shopping mall study would have been underwear and our assumption of standard underwear clo values would be realistic in at least $90 \%$ of cases. We base this estimate on earlier Sydney thermal comfort studies in which large samples explicitly completed the standard ASHRAE Std 55 garment checklists (Rowe 1996, de Dear 1998). Another source of potential bias in the 'unobtrusive observer' collection of clothing insulation estimates in our shopping mall study is the fact that the trained observers were aware of the research hypotheses under investigation in this project. While this bias may not manifest as explicit misclassification of garment types (a short-sleeve shirt is a short-sleeve shirt, regardless of who observes it), the way in which adjectives such as 'light, medium and heavy' are applied to individual garments could be biased by expectations on the part of the trained observers. Given the relatively mild climatic context of Sydney, the vast majority of clothing garments in our database were classified as 'light', and as such, this potential bias would be minor, if present at all.

So while there would inevitably be errors in the raw data collected in this project we believe that they were randomly and uniformly distributed throughout the samples. In a colder climate zone than Sydney's, the potential for underestimating ensemble clo values due to hidden garments or clothing layers in the shopping mall study might become significant, particularly on very cold days. However, in Sydney's mild climate there is no reason to suspect that such underestimation would be large, or systematically correlated with the major independent variables of the study. The focus of this study was not so much to define the absolute value of clothing insulation being worn by the populations using Sydney's shopping mall and office environments, but rather to assess the relationships between clo values worn indoors and both indoor and outdoor temperatures.

\subsection{Gender issues and indoor clothing insulation}

On average, females in the shopping mall study wore marginally heavier clothing than did the males in the 6 mo study. Furthermore, their insulation values demonstrated greater weather sensitivity than the males, as demonstrated by the females' higher between-day variance (represented by $\mathrm{R}^{2}$ ) in mean clo values that could be explained by variations in mean daily outdoor temperature in Fig. 7. Remembering the context in which these data were collected-namely casually attired persons in a shopping mall-the heightened weather sensitivity for female clothing insulation suggests a fundamental difference in clothing behaviour between the two sexes. Casually attired males would appear to follow an informal dress code more than women. The majority of males analysed in the shopping mall study wore the 'casual uniform' of jeans with either T-shirt or regular button-up shirt, regardless of weather dynamics outside. The 'low-clo' option of shorts for the males was encountered in this study very rarely, particularly for the '30 yr and over' age bracket. Women, on the other hand, were visibly more weather responsive in their clothing choices. For example, light, short skirts/dresses or shorts and light short-sleeve tops were more prevalent in hot weather across all age brackets. Although the gender dimension was not formally analysed in the office environment study, the researchers formed the impression that women had heightened weather sensitivity in their clothing patterns than males in that context as well, especially on the casual Friday 'mufti days'.

\subsection{Contextual effects on clothing insulation worn indoors}

A few basic questions arise from the comparisons between the shopping mall and office settings in this study. Firstly, there appears to be a more pronounced seasonal variation in clo values in casual settings (shopping mall) compared to the more formal office setting, but this is probably more the result of the office dress code dampening down the seasonal responsiveness of clothing behaviour than any intrinsic contextual effect. Another factor that could explain this observation is the duration of exposure. 
In the case of the subjects in a shopping mall, they may expect to spend a reasonable part of their shopping trip actually exposed to outdoor weather conditions, and they may dress accordingly. In contrast the office workers may recognise that the duration of their exposure to office indoor climate will be more significant than the outdoor setting, and therefore the clothing insulation choices may reflect that relative weighting of exposure durations. Thirdly, there appears to be significantly greater inter-individual variability in clo estimates in casual settings, suggesting that inter-individual differences in thermal comfort preferences are being accommodated by casual (unregulated) clothing patterns, where individuals are free to find their own thermal equilibrium by dressing however they wish. That is, given the chance, people will exercise the adaptive opportunities (Baker \& Standeven 1996) available to them in the form of clothing choice and adjustments. A logical extension of this line of reasoning is that there presumably must have been more people enjoying thermal comfort (or, alternatively, fewer experiencing thermal discomfort) whenever and wherever they had the adaptive opportunity to behaviourally thermoregulate their clothing.

\subsection{Effects of indoor climate on clothing insulation levels worn indoors}

Indoor temperatures prevailing in the shopping mall study had no statistical association with clo levels being worn inside the mall whatsoever. This can presumably be put down to the very limited amount of day-to-day variance in the department store's indoor temperatures during the 6 mo study. Similarly, in the office building study there was a negligible statistical relationship between clo levels worn inside and concurrent indoor temperatures. However, the extremely limited variance in both the predictor (indoor temperatures) and the dependent (indoor clo) variables precluded any other finding being made with the current data.

\subsection{Effects of outdoor weather and climate on indoor clothing insulation}

Visual analysis of the indoor clothing and outdoor weather time series in this study indicates a relationship between the 2 variables. The shopping mall clothing insulation observations in Fig. 4 show a clear downward trend in clo levels from winter (mid-year) into summer (end/start of year). The most prominent exception occurred towards the end of November (late spring), when clo levels spiked upwards to levels not seen since the depths of winter, but this seems to be accounted for by the sudden cold snap that occurred in Sydney's weather in that week (Fig. 3). There were obvious variations in daily average clo values of about 0.2-0.3 clo amplitude, with a periodicity spanning a couple of days-roughly corresponding to the synoptic-scale variations evident in the outdoor temperature trace in Fig. 3. A more quantitative analysis of the relationship between clothing and weather indicated that more than half of the day-to-day variance in mean (between-subjects) clo levels observed inside the shopping mall was accounted for by concurrent outdoor daily temperatures (Fig. 5). However, it should be remembered that the present study's data were collected from short-term visitors to a shopping mall. It seems reasonable to expect that the relative significance of indoor versus outdoor temperatures on clothing behaviour will be strongly influenced by the relative duration of exposure to both atmospheric environments.

Compared to the shopping mall study, the office clothing insulation data in Fig. 10 revealed a more complex relationship with outdoor temperature. The clo levels observed in the office on Mondays through Thursdays were remarkably homogenous, with daily averages falling consistently between 0.7 and 0.8 clo. Even on 26-27 November, when a heat wave with maximum temperatures reaching into the high 30 s occurred, the formal business attire indoors remained at the usual 0.7 clo. However, during Fridays, when the office workers were permitted to dress casually, there was a much greater variability in thermal insulation being worn. Clo levels on casual Fridays during the coolest month of the study (October; Fig. 10) were generally heavier than during the other weekdays at that time of year. But once the summer weather set in, the casual Friday clothing insulation levels worn in the office were as much as 0.2 clo lighter compared to Mondays through Thursdays.

The disconnection between formal business attire clo levels indoors and concurrent outdoor weather is visually apparent in Fig. 11. In contrast, day-to-day variations in casual Friday clo levels were much more closely related to outdoor temperature $\left(\mathrm{R}^{2}=0.44\right.$; Fig. 12b). This figure is possibly an underestimate of the true correlation because of the small numbers of Fridays falling within the study period compared to the other 4 days in the working week.

The evidence presented in this paper supports our earlier findings that outdoor temperatures influence the clothing levels worn indoors (de Dear \& Brager 1998, 2001). The effect seems most pronounced in situations where people have some autonomy over what they wear, but just how this proposed cause-and-effect 
linkage actually works is an interesting question in itself. It is not difficult to understand how the temperature of the indoor microclimate surrounding the human body exerts an influence on clo levels. Indoor temperature directly impacts the body's heat balance, skin temperatures and skin wettedness, which are, in turn, the main thermophysiological drivers for thermal discomfort ((ASHRAE 1993, Gagge et al. 1986). In conventional thermal comfort theory we regard the motivation for clothing selection and indeed, any other thermoregulatory behaviour, as being proportional to the intensity of conscious sensations of thermal discomfort:

indoor climate $\Rightarrow$ body heat balance $\Rightarrow$ physiological strain $\Rightarrow$ thermal discomfort $\Rightarrow$ behavioural thermoregulation (clothing)

So if that's the causal chain linking indoor temperatures to indoor clothing insulation levels, how can outdoor temperature exert an effect as well, given that the indoor climate of both settings studied in this paper were completely dissociated from outdoor temperatures (i.e. the buildings had centralized HVAC in operation)? The answer may lie in the timing of exactly when clothing decisions are made. The process of getting dressed in the morning involves many decisions about garment selection and overall ensemble thermal properties, and we expect that these decisions are informed, in part, by our memory of what thermal environments were like outdoors yesterday, and possibly also what they are forecast to be like today. Even office-workers who spend only a small fraction of their waking hours outdoors are exposed to the elements, and yesterday's short-duration outdoor exposure exerts a major influence on their clothing decisions, over and above their expectations of the indoor climates they are likely to encounter in the course of their working day.

When we more closely consider the effect exerted by today's outdoor temperature on clothing decisions, we come up against the question of just how can a daily mean temperature for a day that has not actually happened yet exert an influence over our clothing selections before we have even left home in the morning. Even the outdoor temperatures prevailing at the very same time as our clothing decisions are being made are, in many instances, yet to be experienced because our homes' indoor climates are often divorced from their outdoor environment. Part of the answer may simply be that we intuitively expect today's temperature to be comparable to yesterday's, but another possibility may well be that we base our decisions on meteorological forecasts, as disseminated through the mass media which we routinely refer to at the time of our clothing decisions. Breakfast TV and radio broad- casts the world over disseminate the latest meteorological forecasts several times every hour, and morning newspapers provide the same service in print.

To examine this hypothesis more closely, we extracted Sydney's daily maximum and minimum temperature forecasts issued in the very early morning of each day during the shopping mall study (12 August 1996 through 31 January 1997). This involved scanning 6 mo of microfilm archives for Sydney's main daily newspaper (The Sydney Morning Herald). These forecasts would be similar if not identical to those issued to other media outlets such as radio and television, since their source was the same, namely the Australian Bureau of Meteorology. Therefore we are confident that they are representative of the information that the subjects of our study were exposed to when they were making their clothing decisions in the morning.

Examining the 'weather memory' hypothesis first, $47 \%$ of the day-to-day variance in average clo values in the shopping mall study was accounted for by yesterday's mean outdoor temperature, as indicated by Fig. 6. The explained variance increased to $54 \%$ when today's forecast mean outdoor temperature (i.e. mean of forecast max and min temperatures) was used instead of yesterday's observations. Various combinations of independent models were run, but the highest scoring regression model combined both the 'memory' and 'weather forecast' hypotheses together:

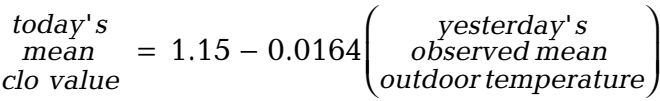

$$
\begin{aligned}
& -0.0178\left(\begin{array}{c}
\text { today's } \\
\text { forecast } \\
\text { maximumtemperature }
\end{array}\right)
\end{aligned}
$$

All terms in Eq. (2) were statistically significant ( $<<$ $0.05)$, and $59 \%$ of the variance in day-to-day clo values is accounted for by the model described above ( $<<$ 0.0001 ). It should be noted that the 2 'independent variables' in the model were themselves significantly correlated $\left(R^{2}=0.39\right)$, which renders the coefficients in the model unstable. Nevertheless, this analysis lends at least support to the 'weather memory' and 'weather forecast' hypotheses of clothing decisions.

Fig. 6 represents another view on the 'weather memory' hypothesis in relation to the shopping mall data. In this figure it can be noted that mean temperature on Day $x$ had the strongest correlation with clothing insulation levels being worn in the shopping mall on Day $x_{\text {, }}$ with $52 \%$ of the variance being accounted for. But the correlation between clothing on Day $x$ and temperature on Day $x-1$ was also quite strong $\left(R^{2}=0.37\right)$, and even Day $x-2$ exerted some influence $\left(R^{2}=0.20\right)$. It 
seems probable that part of the correlation from previous days can be explained in terms of the autocorrelation occurring between successive days' temperatures, but it also seems plausible that the subjects' thermal memory exerts an influence on clothing behaviour via thermal expectations.

\subsection{Indoor clothing and energy consumption in the built environment}

In tropical, temperate and cold climate zones, the single largest impact exerted by an office building on its outdoor environment throughout its entire life cycle results from the energy used creating a comfortable indoor climate (e.g. Roulet 2001). As noted by Holz et al. (1997) in a series of building energy simulation sensitivity analyses, clothing represents one of the most significant comfort parameters influencing heating and cooling loads. An attempt to quantify the significance, Newsham's (1997) simulation study used a standard dynamic energy simulation package (FENESTRA) to 'construct' a virtual office space located in Toronto, Canada. Heating, cooling and fan energy consumption of the HVAC system were taken from FENESTRA's outputs. Thermal comfort conditions were assessed in the simulated indoor climates using the conventional indices of predicted mean vote (PMV) and predicted percentage dissatisfied (PPD), calculated for each time-step (Fanger 1970). The office building simulation was run through a sample of days from Toronto's typical reference year (TRY) of meteorological data under a variety of operational scenarios. At one extreme was the 'fixed-clothing' scenario, in which the clo value of the hypothetical occupants within the space was prescribed, as per the usual comfort standards such as ASHRAE Std 55 (ASHRAE 1992). At the other extreme was the 'variable-clothing' scenario, in which the occupants were permitted to adjust their clothing from a minimal socially acceptable level up to the maximum practical indoor level, as indicated by various published field studies of thermal comfort.

Newsham's analysis of total annual heating, cooling and fan energy was revealing (Newsham 1997). Treating the heating, cooling and fan energy under the 'fixed-clothing' scenario as $100 \%$, it was reduced by 6 , 15 and $41 \%$ for the 'very-limited-clothing-adjustment', 'limited-clothing-adjustment', and 'variable-clothingadjustment' scenarios respectively. In the latter case, the thermostat deadband operating within the simulated building could be widened without compromising comfort because more extreme temperatures could be accommodated by clothing adjustments. It is interesting to consider the implications of Newsham's study for the present results. Markee White's (1986) study suggests that an office environment with a formal dress code is the closest approximation of Newsham's 'fixed clo' scenario. The 'casual Fridays' (mufti days) in our Sydney office study would be akin to Newsham's 'variable-clothing-adjustment' scenario. So in the Toronto context, heating, cooling and fan energy savings accruing from the abandonment of a formal dress code in office buildings could be of the order of $40 \%$ $\mathrm{yr}^{-1}$. Mapping these back-of-the-envelope calculations to Sydney is not so simple, but if we accept that the energy inputs to cooling are generally higher than heating (due to differentials in thermodynamic efficiencies of the 2 processes), the $40 \%$ could well be a significant underestimate in a warm climate zone. If nothing else, these speculations point towards some very useful avenues for future research in which the seasonally varying clothing ensembles of the type observed during 'casual Fridays' in the present Sydney office study are simulated within a software package such as FENESTRA in a climate zone where HVAC energy is dominated by cooling loads. Such a study might indicate the true costs in terms of energy and greenhouse-gas emissions of 'formal business attire' policies in the workplace.

The literature review at the start of this paper noted the findings of the ASHRAE RP-884 adaptive thermal comfort project (Figs. 1 \& 2). There appeared to be roughly the same amount of indoor clothing insulation variance explained by outdoor weather in the present studies $\left(0.44<\mathrm{R}^{2}<0.52\right.$ in Figs. 5 \& 12) compared with earlier studies such as those depicted in Fig. $2\left(\mathrm{R}^{2}=\right.$ 0.49). This broad agreement occurred despite the widely discrepant time scales of analysis in the 2 studies. In the earlier adaptive model study, the insulation (clo) value in question represented the entire sample within a single building averaged for the duration of the study (typically a few weeks), while the outdoor temperature in that analysis was an average of the daily maxima and minima across the same period. However, the outdoor temperature observations in the present shopping mall study were averaged across a typical daily sample size of about 45 subjects and lasted for $1 \mathrm{~d}$ only.

If outdoor conditions can account for about half the variance in the level of clothing insulation worn inside buildings when indoor and outdoor climates are virtually disconnected, it becomes interesting to speculate what the percentage of explained clo variance might be in low-energy buildings, where indoor and outdoor climates are more closely related. Free-running buildings (Humphreys 1981) are those in which neither heating nor air-conditioning are operating and the degree of correlation between indoors and outdoors can be quite high, depending on the thermal proper- 
ties of the building envelope and ventilation rates. The hypotheses and findings in this paper lead us to expect that the linkage between indoor clo values and outdoor weather would be even stronger in free-running buildings than we observed in air-conditioned settings. Clearly a corporate dress code has no place in such buildings, because it undermines this key mechanism of personal thermal adaptation. Indeed, this issue has been flagged in the forthcoming revision to ASHRAE Std 55, which specifically precludes application of the adaptive model of thermal comfort in naturally ventilated contexts where the building occupants are not free to adjust their clothing to suit their own thermal comfort preferences (ASHRAE 2002, de Dear \& Brager 2002).

The adaptive comfort standard (ACS) described in detail elsewhere (ASHRAE 2002, de Dear \& Brager 2002) prescribes comfortable and permissible indoor temperatures on the basis of concurrent outdoor weather conditions. The key independent variable in the adaptive model underpinning ACS is the mean monthly outdoor air temperature. In fact, the raw data that went into the model used weather data integration periods ranging from a couple of days up to a couple of weeks - in effect, the duration of each individual building survey, of which there were 160 in the entire RP-884 database. The question of what is the optimal time frame for the outdoor-temperature term in adaptive models has not been thoroughly addressed to date. While the reference period of 1 mo was selected for implementation in the ACS because of its widespread availability in published climatologies the world over, a more accurate time scale is probably shorter than this (Nicol et al. 1995). The findings in the present field studies of clothing behaviour provide some guidance as to what the optimal integration period might be. In particular, the correlation coefficients (or $\mathrm{R}^{2}$ ) for clo values on Day $x$ with outdoor temperatures on Day $x$, Day $x-1$, Day $x-2$, Day $x-3 \ldots$ Day $x-n$, as plotted in Fig. 6, show a remarkably smooth exponential decay with time, with a half-life of about $2 \mathrm{~d}$. All coefficients going back to Day $x-7$ were statistically significant at the 0.05 level or better. This information provides a rational basis for defining the most appropriate mean outdoor temperature driver for adaptive models of thermal comfort $\left(T_{\text {mot }}\right)$. In our opinion, the ideal outdoor temperature function for adaptive comfort guidelines is an exponentially weighted running mean spanning the last 7 days. While today's temperature, forecast or observed, holds significant predictive power with regards to clothing insulation, it cannot be included in such an adaptive algorithm, because the daily maximum will not have occurred by the time it is actually needed for calculation purposes. This $7 \mathrm{~d}$ integration period is short enough to reflect the perceptual impacts of recent weather dynamics, but also long enough to capture 'weather memory and persistence' effects on human clothing behaviour.

The weighting coefficients for our proposed running-mean weekly outdoor temperature adaptive algorithm $\left(T_{\mathrm{mot}}\right)$ were derived from the exponential function plotted in Fig. 6. The actual calculations are detailed in Table 3.

These weighting coefficients can be used to calculate the appropriate mean outdoor temperature $\left(T_{\mathrm{mot}}\right)$ for subsequent input to an adaptive indoor temperature algorithm:

$T_{\text {mot }}=0.34 T$ Day $x-1+0.23 T$ Day $x-2+0.16 T$ Day $x-3+$ $0.11 T$ Day $x-4+0.08 T$ Day $x-5+0.05 T$ Day $x-6+0.03 T$ Day $x-7$

and then the adaptive algorithm for indoor comfort temperatures in a naturally ventilated or free running building (de Dear \& Brager 2002) can be written as

$$
\text { comfort temperature }\left({ }^{\circ} \mathrm{C}\right)=0.31 T_{\text {mot }}+17.8
$$

and the acceptable range of temperatures is defined as the optimal comfort temperature (Eq. 4 ) $\pm 2.5^{\circ} \mathrm{C}$ for $90 \%$ acceptability, or $\pm 3.5^{\circ} \mathrm{C}$ for $80 \%$ acceptability (ASHRAE 2002).

Given that the adaptive model in Eq. (4) is relevant to naturally ventilated buildings, it may not be immediately apparent what purpose could be served by performing real-time calculations of temperature optima, or indeed acceptable temperature ranges, since these buildings, by definition, lack an HVAC response mechanism. However, buildings with hybrid ventilation are very relevant to Eq. (4). The concept of hybrid ventilation is a simple one-the building operates in naturally ventilated mode whenever the outdoor atmospheric environment is conducive to thermal com-

Table 3. Weighting coefficients for an adaptive algorithm based on the exponential decay of outdoor weather influences on indoor clothing insulation decisions. The variable $y$ represents the coefficient of determination $\left(R^{2}\right)$ for the relationship between mean clo levels worn indoors and outdoor mean daily temperatures (Fig. 6)

\begin{tabular}{|lccc|}
\hline \multicolumn{2}{|c}{ Day number $x$} & $y=0.69 \mathrm{e}^{-0.3688 x}$ & $T_{\text {mot }}$ weighting \\
\hline Today & 1 & 0.477 & 0.00 \\
Day $x-1$ & 2 & 0.330 & 0.34 \\
Day $x-2$ & 3 & 0.228 & 0.23 \\
Day $x-3$ & 4 & 0.158 & 0.16 \\
Day $x-4$ & 5 & 0.109 & 0.11 \\
Day $x-5$ & 6 & 0.075 & 0.08 \\
Day $x-6$ & 7 & 0.052 & 0.05 \\
Day $x-7$ & 8 & Day $x-7^{-\cdots}$ & 0.03 \\
& \multicolumn{3}{c}{$\sum^{2} y=0.989$} \\
\end{tabular}


fort indoors, but then switches over to an active HVAC system whenever outdoor conditions become too extreme to manage passively (International Energy Agency Annex 35 2001). Typically the control of hybrid buildings is performed by a Building Management System (or Energy Management System), and these facilities oftentimes have an automated weather station on or near the building in question. Such a configuration can readily compare continuously recorded indoor conditions with the corresponding range of acceptable indoor temperatures (Eq. 4) based on the last 7 days' outdoor temperatures (Eq. 3), and then switch the hybrid building over to active HVAC mode whenever current conditions fall outside acceptable ranges.

An important caveat regarding this proposed algorithm for $T_{\text {mot }}$ is that it is only relevant to the context in which its underlying data actually come from Sydney, Australia. There may well be different findings in other parts of the world, particularly where the day-to-day weather and temperature fluctuations have a different amplitude and periodicity. The most comparable study to the present one was conducted by Nicol et al. (1995) in Oxford, UK. In a 6 wk longitudinal thermal comfort research design, they estimated a half-life on the exponential decay relationship to be between 3 and $4 \mathrm{~d}$, or about twice as slow as that found in the current study. However, we are unsure whether this difference in time constant is due to differences in weather dynamics between Sydney and Oxford or the fact that the dependent variable in the Oxford study was thermal comfort questionnaire vote and not clothing insulation value, as used in the current study.

Another caveat regarding our proposed algorithm for $T_{\text {mot }}$ is that the clothing data from which our $7 \mathrm{~d}$ weighting coefficients were derived (Eq. 3) may not correspond with ideal thermal comfort. We did not ask our shopping mall subjects about their subjective thermal comfort states because direct contact with them was precluded by our unobtrusive mode of observation. In defence of the unobtrusive method we contend that our subjects could not have been very uncomfortable, because they were not motivated to change their clothing to thermally more appropriate insulation levels. If they were seriously uncomfortable in the shopping mall the normal response would have been to leave. Nevertheless, the assumption of thermal comfort states is less than ideal, so the $T_{\text {mot }}$ equation (Eq. 3) developed out of our data could be improved with future research based on clothing behaviour in a set-

ting where thermal comfort can be assured more directly.

We also recognise that the utility of such an exponential function for the adaptive model is going to be restricted to applications in which real-time weather observations are available, typically from an AWS on the same site as the building in question. In the absence of real-time data there will be no practical alternative to the climatological monthly norms (i.e. relying on the published mean monthly temperatures for input as $T_{\text {mot }}$ to Eq. 4), as published by the local meteorological service.

The Intergovernmental Panel on Climate Change (IPCC) reports that global average surface temperature is projected to rise by 1.4 to $5.8^{\circ} \mathrm{C}$ by 2100 , relative to 1990 (Cubasch et al. 2001). In order to manage this projected rise the United Nations Climate Change Conference in Kyoto (1997) set in place the Kyoto Protocol in which some developed nations agreed to limit their greenhouse-gas emissions, relative to the levels emitted in 1990. The implications of the present study for the issue of greenhouse-gas emissions are simple-that the ability to effect energy conservation and reduce greenhouse-gas emissions attributable to the commercial building sector will be directly impacted by the degree of flexibility that building occupants have over the clothing they wear indoors. Newsham's investigation (described earlier) into the relationship between clothing adjustments and energy savings in Toronto buildings (Newsham 1997) is just as relevant to the issue of greenhouse-gas emissions as it is to energy consumption. 
Finally, we hope that the research reported in this paper might stimulate innovation within the clothing industry. In particular, the paper provides a strong case for the development of clothing garments that can fully comply with formal office attire dress codes, yet provide the wearer with enhanced adaptive opportunities. This might take the form of more variable clothing garment combinations making up office-clothing ensembles. Alternatively, it may be possible to design insulation variability into individual garments, such as adjustable or even removable linings from jackets, or zippered vents concealed in the design and cut of jackets or dresses.

\section{CONCLUSIONS}

This paper has emphasised the impacts of outdoor weather, past (observed) and future (forecast), on the level of clothing insulation worn inside buildings. While the statistical association has been readily demonstrated, the chain of causation has many links and attenuating factors. Fig. 13 attempts to draw this complexity together in the form of a conceptual model of clothing, buildings, climate and energy. Starting with weather and climate, the outdoor atmospheric environment impacts the energy balance of a given building, and that building's indoor climate responds accordingly. The human occupants of the building maintain their own energy balance with indoor climatic conditions, and the extent to which they rely on physiologic (as opposed to behavioural or engineering) responses to maintain that energy balance determines the magnitude of their thermal discomfort and attendant dissatisfaction. A key behavioural mechanism that attenuates thermal discomfort indoors is the adjustment of clothing insulation levels, but there are several factors, some of them psychological (cognitive, aesthetic, organisational, cultural, etc.) impinging on clothing decisions as well as the usual thermal variables (temperature, humidity, etc.). One of these is the clothing policy of the occupants' employer. Corporate dress codes, as found in the present office environment study, all but extinguish clothing adaptive opportunity. The net result of such policies is to transfer responsibility for comfort thermoregulation away from the individual and towards a building's facilities manager. However, another factor impinging on clothing decisions is outdoor weather, either directly experienced or perhaps forecast by the local meteorological service. This linkage, if given free reign, offers potential to reduce our reliance on external energy inputs (air conditioning and heating) for the maintenance of thermal comfort indoors. In so doing there is also likely to be attendant reductions in greenhouse-gas emissions attributable to the commercial building sector. Energy conservation and greenhouse-gas emission reductions are both premised on relaxation of the restrictions applying to the thermal adaptability of indoor clothing such as corporate dress codes.

Acknowledgements. The authors wish to thank Target stores and the Sitel Corporation for permission to conduct the study at their Sydney premises. Meteorological data were supplied by the Australian Bureau of Meteorology. Prof. Gail S. Brager at the Center for Built Environment at the University of California, Berkeley, is thanked for her comments on various aspects of this project.

\section{LITERATURE CITED}

ASHRAE (1992) ANSI/ASHRAE Standard 55-thermal environmental conditions for human occupancy. American Society of Heating, Refrigerating and Air-Conditioning Engineers, Atlanta

ASHRAE (1993) Physiological principles and thermal comfort. Handbook of fundamentals, Chap 8. American Society of Heating, Refrigerating and Air-Conditioning Engineers, Atlanta

ASHRAE (1997) Physiological principles and thermal comfort, Chap 8. American Society of Heating, Refrigerating and Air-Conditioning Engineers, Atlanta

ASHRAE (2002) Public review draft of ANSI/ASHRAE Standard 55R - thermal environmental conditions for human occupancy. American Society of Heating, Refrigerating and Air-Conditioning Engineers, Atlanta

Auliciems A (1981) Towards a psycho-physiological model of thermal perception. Int J Biometeorol 25:109-122

Auliciems A (1986) Air conditioning in Australia III: thermobile controls. Architect Sci Rev 33:43-48

Baker N, Standeven M (1996) Thermal comfort for free running buildings. Energy Bldgs 23:175-182

Bureau of Meteorology (1991) Sydney: climatic survey. Australian Gov Pub Serv (AGPS), Canberra

Clark RP, Edholm OG (1985) Man and his thermal environment. Edward Arnold, London

Cubasch U, Meehl GA, Boer GJ, Stouffer RJ, Dix M, Noda A, Senior CA, Raper S, Yap Y (2001) Projections of future climate change. In: Houghton JT et al (eds) Climate change, 2001, The scientific basis. Contribution of Working Group I to the Third Assessment Report of the Intergovernmental Panel on Climate Change. Cambridge University Press, Cambridge, p 267-289

Danielsson U (1993) Convection coefficients in clothing layers. KTH doctoral thesis, University of Stockholm

de Dear RJ (1998) A global database of thermal comfort field experiments. ASHRAE Trans 104:1141-1152

de Dear RJ, Brager G (1998) Developing an adaptive model of thermal comfort and preference. ASHRAE Trans 104: 145-167

de Dear RJ, Brager G (2001) The adaptive model of thermal comfort and energy conservation in the built environment. Int J Biometeorol 45:100-108

de Dear RJ, Brager GS (2002) Thermal comfort in naturally ventilated buildings: revisions to ASHRAE Standard 55. Energy Bldgs 34:549-561

Fanger PO (1970) Thermal comfort. Danish Technical Press, Copenhagen

Fountain M, Brager G, de Dear RJ (1996) Expectations of 
indoor climate control. Energy Bldgs 24:179-182

Gagge AP, Burton AC, Bazett HC (1941) A practical system of units for the description of heat exchange of man with his environment. Science 94:428-430

Gagge AP, Fobelets A, Berglund LG (1986) A standard predictive index of human response to the thermal environment. ASHRAE Trans 92:709-731

Goldman RF (1981) Evaluating the effects of clothing on the wearer. In: Cena K, Clark JA (eds) Bioengineering, thermal physiology and comfort. Elsevier, Amsterdam, p 4155

Holz R, Hourigan A, Monkman SRP, Krarti M (1997) Effects of standard energy conserving measures on thermal comfort. Bldg Environ 32:31-42

Humphreys MA (1979) The influence of season and ambient temperature on human clothing behaviour. In: Fanger PO (ed) Indoor climate. Danish Building Research Institute, Copenhagen, p 699-714

Humphreys MA (1981) The dependence of comfortable temperatures upon indoor and outdoor climates. In: Cena $\mathrm{K}$, Clark JA (eds) Bioengineering, thermal physiology and comfort. Elsevier, Amsterdam, p 229-250

International Energy Agency Annex 35 (2001) State of the art of hybrid ventilation, CD-ROM, Ver 2.0. International Energy Agency, Aalborg

Markee White NL (1986) Quantification of factors influencing thermal comfort in an office environment: implications for energy conservation. Thesis, University of California at Davis

McCullough EA, Jones B (1984) A comprehensive database for estimating clothing insulation. Institute for Environmental Research, Manhattan, KS

Editorial responsibility: Robert Davis (Editor), Charlottesville, Virginia, USA
McIntyre DA (1980) Indoor climate. Applied Science Publishers, London

Moser CA, Kalton G, (1971) Survey methods in social investigation. Heinemann Educational, London

Newsham G (1997) Clothing as a thermal moderator and the effect on energy consumption. Energy Bldgs 26:283-291

Newsham G, Tiller DK (1997) A field study of office thermal comfort using questionnaire software. ASHRAE Trans 103:3-17

Nicol JF, Humphreys MA, Raja IA (1995) Developing indoor temperature standards for naturally ventilated buildings. CIBSE Conference. Chartered Institution of Building Services Engineers, London

Nishi Y, Gonzalez RR, Gagge AP (1975) Direct measurement of clothing heat transfer properties during sensible and insensible heat exchange with the thermal environment. ASHRAE Trans 81:183-199

Olesen BW, Nielsen R (1983) Thermal insulation of clothing measured on a moveable manikin and on human subjects. Report, Technical University of Denmark, Lyngby

Parsons KC (1993) human thermal enviornments: the effects of hot, moderate and cold environments on human health, comfort and performance. Taylor \& Francis, London

Roulet CA (2001) Indoor environment quality in buildings and its impact on outdoor environment. Energy Bldgs 33: 183-192

Rowe DM (1996) Some observations on thermal comfort in a commercial office building. Australian Institute of Refrigeration, Heating and Air Conditioning International Conference, AIRAH, Hobart

Woodcock AH (1962) Moisture transfer in textile systems. Textile Res J 32:628-723

Submitted: December 13, 2002; Accepted: May 21, 2003

Proofs received from author(s): July 15, 2003 